\title{
THE "PASSING CLOUDS" OF NATIONALISM IN ANTHEA NICHOLSON AND KAPKA KASSABOVA: CROSS-BORDER RECOLLECTION OF POLITICAL TRAUMA
}

Keywords: global coloniality; postcolonialism and post-Socialism; authoritarian regimes; migrant writing; therapeutic recollection; Anthea Nicholson; Kapka Kassabova.

Abstract: Nationalism re-emerges from contemporary cultural debates under a panoply of controversial perspectives. In some of them like, for instance, the contemporary fields of border studies and the study of migrant cultures and writing, it fairly often takes the shape of an effort to strengthen hierarchies, hold differences together into ideologically 'sterile', supposedly homogeneous units, and to delimit overflowing identities. What binds a great many such contemporary reassessments is the urge to retrace or excavate past experience of nationalism, especially in cases when its purportedly beneficial properties of sheltering nations are brought to such ends as dictatorship, autocratic and authoritarian rule.

The present article ruminates on those violent forms through the medium of two literary works authored by contemporary writers in its attempt to analyse the traumatic, but also prolific potential of re-membering past oppression. The study is concerned with their responses to an excessively violent political form of selfproclaimed nationalism which are worth considering because of their borderline status. Both Anthea Nicholson and Kapka Kassabova fall into the category of migrant writers. Of Georgian and Bulgarian descent, both writing in English, each one of them retraces a remembered and oppressive past experience in an effort that aims to reconstruct the contemporaneity of their countries of origin. Alongside specific contextual details, the investigation meditates on the common features of their fictional responses to a shared past. A meaningful outcome of their retracings is the critical distance that forms between remembered experience and the contemporary state of their birth lands which illuminates in a creative way the problematic achievement and development of state sovereignty.

Rethinking the national at a time when global political, economic and cultural projects coexist with the re-enhanced quests for local narratives of self-location both foregrounds the necessity of strengthening borderlines against overflowing homogeneity and the need to keep alert on the equally unwholesome limits of imposed design. The concept of design forms part of the repertoire of contemporary critics of Modernity, Uzbek-Cherkess Madina Tolstanova one of the major contributors to that now growing field of scholarship, who take vigorous efforts to 'decolonise' some mainstream pronouncements on local premises and experience. Tolstanova considers

\footnotetext{
${ }^{*}$ St. Cyril and St. Methodius University of Veliko Tarnovo, Bulgaria.
} 
Trauma, Narrative, Responsibility

the strategies of 'design' in her critique of postcolonial theoretical thought suggesting in place of the latter's overly schematic models the more comprehensive rhetoric of a "global coloniality", or, as she sees it, a paradigmatic embracing attitude "at the base of [which] stands the idea of classifying humankind in relation to the colonial matrix of power. . One does not need to be colonized in a classical political and economic sense to be subject to such categorizing matrix" (Postcolonial Europe 30). She actually reasons that "global coloniality" can be taken to signify an overall philosophical framework that may underlie various practices of subjugation and attitudes of dependence around the globe. By inference, "decoloniality" refers to both the processes of reworking "coloniality" as a mind-set through particular forms of experience, and the attaining responses triggered out from those who have been colonised. Tolstanova is convinced that the response of the decolonised subjects is more genuine and trustworthy than that elicited within the imperial (or former imperial) elite, which makes her paradigm reductive, to some extent. Nevertheless, the concept of "global coloniality" turns out to be particularly helpful to critical attempts that aim at balancing between the theoretical models of postcolonialism and post-Socialism, as "global coloniality", in spite of its elusive and rather abstract scope, can be tailored to bridge the gap between these close yet, in many respects, distinctive forms of political, economic, social and cultural organisation. What matters here is that imbricated in the mechanisms of propagation of global coloniality is the desire to design the time, space, bodies, politics and geopolitics of the "knowledge, being and perception" (Tolstanova, Design Philosophy 51-2) that regulate subjectivities. In that case, the critical attempts to unravel the problematic articulation of sovereignty under post-dependence conditions (be it postcolonial, post-Soviet or post-Ottoman ones) should take into consideration both the euphoric experience of 'tearing' design in a quest for disconnection from the ruling Nationalism; and the nostalgic recollection of what many, especially the older generation of survivors of authoritarian regimes, might refer to a loss of order and direction. It is in this uncertain theoretical space and actual experience that I will attempt to locate two authors who share in such postdependence quests in very close proximity - from within the apparatus of Soviet power - post-Socialist Georgia, and from its satellite outskirts - post-communist Bulgaria. Though distinctive, the two authorial voices share a common space of uncertain self-location, both because they belong to migrant writers (which endows them with the expanded optical vision of multi-placedness, i.e. being both 'outsiders' and 'insiders' to their places of origin), and because both of them articulate the ongoing transition between a 'designed', 'planned' mode of individual and collective self-location under the totalitarian regime, and its posterior dissolution into memories, expectations, and, generally, narratives that seek to repopulate the opening gaps of regained sovereignty. What brings together Georgian Anglophone Anthea Nicholson and Bulgarian Anglophone Kapka Kassabova (both contemporaries and critically acquainted with one another) is their simultaneous distance from and presence in the narrated events - remembered, recast and relived both therapeutically and traumatically as part of the impasse and omnipresence migrant writers experience.

Anthea Nicholson's novel "The Banner of the Passing Clouds” (2013) owes its title to Boris Pasternak's poem "Still More Sultry Dawn”, (“Еще более душный рассвет" in original (1917)) and rewrites the appeal in the poem, the prayer of the 
Trauma, Narrative, Responsibility

lyric speaker to be spared from the conversation of the crowding grey clouds. The symbolic 'heaviness' of the morning enters Nicholson's fictional world as a constant reminder of the inconsolably painful coexistence of individual stories beneath the seemingly opaque but actually porous film of dominant narratives imposed by political regimes of tightly surveyed ideological design. The symbolism of the "sultry dawn" that runs as the undercurrent of a familial and a larger collective experience conveys the paradox of a distorted spatiotemporality, a vortex that forms by two colliding currents of space and time. A third flow, detectable at the structural level of the narration, forms as the narrator, shifting from $1^{\text {st }}$ person confession to invisibility, uncoils the magnetic reel of the protagonist's recorded personal guilt, family history and the daily life and songs of Soviet Tbilisi. The text is retrospective. In the first part, the protagonist, an ethno-musicologist who works as a collector of ethnic songs in the streets of Tbilisi, is constantly impeded in his private life and public activity by the embodied shadow of Stalin (comrade Iosif Dzhugashvili) whose name, negligently bestowed upon his identity by a hospital official, turns into his shadow self. Interestingly, this case of identity splitting bears semblance to Dr Jekyll-Mr Hyde syndrome only superficially. Stalin's personality never overtakes his namesake's life completely - initially, he dwells between his ribs (and prevents him from singing), then moves downwards to his intestines until finally he shrivels and is expelled by the protagonist's bloody defecation. Significantly, the dissolution of the 'steel man' coincides with Georgia's first years of post-Soviet independence, marked by a parallel dissolution of the meticulously designed structures of control, surveillance and ideological indoctrination. The novel's protagonist, then, certainly joins a multitude of literary figures (like Saleem Sinai in Salman Rushdie's novel Midnight's Children or Sarah Nour El-Din in Rabih Alameddine's I, the Divine) who stand as embodiments of collective history. More than that, such characters, mostly positioned at times of temporal or spatial transition, become "living borderlines", the psychological and bodily projection of the unresolved silences that accompany any such passage. In Iosif's case (meaning Nicholson's protagonist), the grotesque transformation of his indweller traces the traumatic pathway of ingestion of Sovietism, clogged by the lovehate transitional relationship with one of its emblematic faces - Stalin. Stalin's presence in the inside of a common human subject also implies a certain panoptic trend of self-control, a kind of imprinted identity which follows as the outcome of extensive Soviet indoctrination. The novel's end, however, stages the beginning of the protagonist's recuperation from his ruptured identity and body, paradoxically, by embracing the inflicted rupture. In that process he is helped by his reconnection to more permanent entities than the "banners" of the changing leaders of passing time earth, faith and songs. From a psycho-mythological perspective, the protagonist's bearing of Stalin's name as both a controlling but also a controllable principle could be read as a rewriting of the ancient tradition of naming the aspects of human destiny as individuated agents - daimons. In Hesiod's Theogony, for instance, as Marina Warner observes, Metis, "a daimon who dwells within the paternal womb of Zeus . . . no longer possesses the individuality of separate physical existence, by which we understand her to be a person. But her powers remain unimpaired . . . Zeus's incorporation of her into his being robs her of freedom of agency but does not diminish her force" (73). I suggest such figuration of controllable agency is what Nicholson 
presents in her characterisation of Stalin as a powerful, but ingested figure. His ultimate dissolution points to the process of ingestion as a more effective pathway to obtaining meaningful sovereignty than the trajectory of violent rejection or strategic forgetfulness. At least, the ingestion scenario proves to be an inevitable element of the process of personal and collective "healing" in the aftermath of oppressive regimes.

The first part of the novel which tells about the birth, growth and adolescence of its problematic protagonist, with Stalin occupying a substantial part of his identity (his breathing and heartbeat), projects Soviet design as a seemingly grandiose but actually flimsy structure. Its architectural, agricultural, technological, military and social projects, for instance, are ontologically cast through the metaphor of the "passing clouds". Thus, in Part I, the narrative which is a remembered and, therefore, retrospective account, occupies a temporal slot between Khrushchev and Gorbachev's rule, hailed by raising and lowering banners with their portraits. The period is likewise "recorded" by the "red needle" and "turning spools" of the protagonist's magnetic recorder with its "particles of magnetic iron oxide lining up to express each nuance of sound" (Nicholson 29). The alignment implied in the recording suggests its possible inclusion in the registers of Soviet collections of information, immobilising the recorded sounds of space and time as 'memories' intended for the future generations. This activity, in the end, turns out to be a futile exercise of the regime's self-exaltation. Explaining the mechanism of magnetic recording, the narrator-protagonist Iosif himself concludes that "The only things I need are the intangible sounds of song ... . My reels of tape are the colour of dried blood. The colour of spilt blood" (76). This comment also comes as a confession posterior to his involuntary complicity in the imprisonment of his brother Paolo (significantly named after suicide-committing Georgian poet Paolo Iashvili) and his wife Maia, both brilliant singers, by offering KGB a mistaken tape-recording of their dream-like plan to hijack a plane and escape abroad. But the manner of recording itself, pinning down particles of breathed sounds, is also presented as the production of a herbarium, a parallel imprisonment of the living streets, swarming lives, a singing Tbilisi, in the linear formality of planned time and space. Maia who survives seven years of imprisonment after Paolo's death, notes earlier, "Look at the birdies, they don't need to be saved for posterity. And anyway I never remember my songs ... Here today, gone tomorrow. Just like the wheat! Poof!" (75). The freedom of the song, its breathed vitality and spreading sound is represented as a counter narrative of fleeting time against the "heavy" aesthetics of socialist reality. The ethics of momentary existence, itself theorised by a variety of Modernist movements, is, paradoxically, represented as more permanent than the planned "permanence" of rising tower-like collective residences, planned trolley lanes, artificially nurtured wheat fields, artificially designed career opportunities. Throughout the narrative, all forms of designed permanence develop in parallel with patches of disordered universe: parallel to the magnetically recorded songs spreads the chiming of church bells, parallel to the cultivated fields - "stars . . streaming away as if someone had opened a sluice in the dam of eternity" (49); parallel to his plans, Iosif suffers his parents' and brother's deaths, but also embraces his resurrected love for Maia in the brokenness of a "sultry dawn". The narrated story ends acoustically and amidst ruins but hints at certain rejuvenation. An orphaned world is 
singing with the morning bell a hummed refrain that both laments loss and celebrates life’s vigour, “nau nani nau nani nana nau ...” (289).

The quest for dismantling the structures that can be approached as a tightly locked "prosthesis" of spatiotemporal, collective and personal expanse for selfdefinition is part of a contemporary cultural trend registered by Tolstanova in her dissection of the post-dependence condition. A turning point in this movement, she argues, could be traced down to philosopher Enrique Dussel's observation that "the predominant political will to power should change to the will to life" (quoted in Tolstanova, Design Philosophy 55). This conviction seeks to temper the impulses for appropriating, 'normalising' and 'steering' local forms of knowledge to the service of mainstream theoretical models or solutions; rather, the "will to life" encourages an attitude of humility privileging "local remedies" found in stories of survival over mainstream authoritative pronouncements. In this sense, Nicholson's text presents us with a fictional redemption of Georgia as a culturally specific locus whose 'sovereignty' draws on certain ontological permanence engendered in its particular ways of claiming life's essentials. We should, however, bear in mind that Nicholson writes from the position of a cross-cultural author whose reconnection to native soil may partially entail an effort to produce an imaginary place, a "homeland of the mind" ${ }^{1}$ in a manner that problematises the unreliability of emotional remembrance. In the author's note at the end of her novel, she explains that her story was inspired by an actual tragedy - "In 1983 a group of young 'intellectual' Georgians hijacked an Aeroflot plane with the intention of crossing the border to live in the West. Their plan failed with tragic consequences" (291), quickly specifying that "The story I have written is not theirs, although I have . . . borrowed something of their mad, sad dream" (291). Stories like that one naturally fit in the repertoire of what can be approached as a discourse of victimisation, i.e. a pronouncement that often views "past suffering" as a source of "power and privilege" (Todorov, quoted in Kostova Betraying the Event 35). Ludmilla Kostova who applies this discursive model as she investigates representations of South Eastern Europe in British fiction and drama ${ }^{2}$ is certainly right to point out the problematic ethical dimension of such stance - borrowing from Tzvetan Todorov's vocabulary of thought she concludes that "While Todorov does not doubt the need for such a history, which should shed light on aspects of the past that were previously erased or marginalized, he strongly objects to the uncritical idealization of victimhood and to its exploitation as a source of moral dividends" (Betraying the Event 35).

With a critical discernment alert to this message, we should also bear in mind that the "moral dividends" of Nicholson's novel consist of something more than rendering Georgia visible to the world beyond its borders. Written in English and apparently intended for western audiences, the story of Iosif, Paolo and Maia emerges already translated into a medium of transnational appreciation. Nicholson who benefits from her migrant niche in the interstices between cultures, does manage to

\footnotetext{
${ }^{1}$ See Rushdie's eponymous collection of essays Imaginary Homelands: Essays and Criticism, 1981-1991(1992).

${ }^{2}$ See the chapter "Victimization and Its Cures: Representations of South Eastern Europe in British Fiction and Drama of the 1990s".
} 
locate Georgia's problematic sovereignty in a similar interstitial environment. At the same time, revisiting the instances of accumulated violence in a fictional return to experienced oppression helps address "the necessity of disinfecting the space of the post-totalitarian post-dependence” (Tolstanova, Postcolonial Europe 37).

On the other side of the Black Sea, Bulgaria's post-totalitarian trajectory becomes subject to similar "exorcism” in Kapka Kassabova's novel Border. A Journey to the Edge of Europe (2017). Her cross-border writing is studied in detail in Kostova's article "Writing Across the Native/Foreign Divide: the Case of Kapka Kassabova's Street Without a Name" which dwells on the variable optics of Kassabova's migrant perspective. Kostova even detects an element of latent "colonialism" in the way Kassabova carries out her project, a book entitled Street Without a Name (significantly commissioned by the British publisher Portobello Books $^{3}$ ), of making Bulgaria "visible" to western eyes, which also implies redressing its obscurity not least as a site of tourist interest. Kassabova's semi-detached position is further established by her family's wished migration from the "homeland" for economic reasons, but also due to the general sense of helplessness that marks the eve of Bulgaria's transition to democracy. She frequently revisits that actual and symbolic borderline in her writing, but Bulgarian readers tend to be more critical of her fleeting returns and attempts to "relocate" both herself and her origins to an appreciation of border lives. There is something in her writing that imbues her genuine experience with a more distanced spirit of condescension and a patronising attitude which may even take the dimensions of stereotyped representation - particularly in her comments on certain external markers of difference as ethnic dress and appearance, economic or intellectual status. These forms of subtle colonialism are inevitably engendered by the vantage point of her creative projects - to describe, unravel, remember, translate past and present experience from the position of someone who needs to appropriate, temporarily, even if as a visitor, signposts of retreat in her migrant domesticity. These aspects of her writing are carefully problematized in Kostova's article.

It is, however, precisely that position of unsettled, roaming, probing inspection which enables Kassabova to narrate her journeys as a flâneur ${ }^{4}$ possessing the faculty of a "fleeting gaze" that Madeleine Hurd, Hastings Donnan and Carolin Leutloff-Grandits see as instrumental in reconsidering "a palimpsest of meanings and historical referents ... . whose afterlives awaken the observer to new conceptual constellations" (4). Obviously, borders are such "palimpsest" sites since they not merely contain national entities 'cosmetically' on cartographic maps, but they also operate as deeply-burrowed layers of experience that contour the "breathing" of collective bodies (such as nations are), their expansion and shrinking. Kassabova's choice to inspect the 'Edges' of the post-Communist south-eastern Europe which overlap with a patch of 'nobody's and everybody's' land between Bulgaria, Greece

\footnotetext{
${ }^{3}$ Kassabova herself acknowledges in an interview that "they ... w wanted a book about Bulgaria because there aren't many... Bulgaria is such an obscure place in the Western mind” (quoted in Kostova, 167).

${ }^{4}$ The term, first introduced by Walter Benjamin drawing on the poetry of Charles Baudelaire, is now recaptured by Olivier Thomas Kramsch to conceptualize the contemporary figure of the migrant and the itinerary of border crossing. See chapter 1 of Migrating Borders.
} 
and Turkey, is, in her words, part of a comparative design. In the introduction to her book she explains that her journey was partially prompted by the growing corporate ownership and deforestation of Britain's fringe lands, in particular, rural Scotland ("which counts as a sort of a periphery if your centre is 'the central belt' of Edinburgh and Glasgow, and even more of a periphery if your centre is London ... I became curious about my native Balkan peripheries"). ${ }^{5}$ Citing the awkward notional division of European "centres" and "peripheries", already overly exploited in the academic jargon, the narrator's curiosity may be genuine though it betrays, again, the lurking avidity of the colonizing gaze. Just a few lines later, however, her naïve observation is counteracted by the pervading tone of personal anxiety that becomes the catoptric (optically distorting) lens of her quest, "But the real emotional impulse behind my journey was simple: I wanted to see the forbidden places of my childhood, the oncemilitarised border villages and towns, rivers and forests that had been out of bounds for two generations". ${ }^{6}$ Then, she goes on discussing the tricky invisibility of borders even to those who live within them, aligning herself across national borders with all "urban elites" who are mostly ignorant about the condition of 'peripheral' lands. Finally, she concludes that "borders are ubiquitous - visible and invisible, soft and hard, [with and inside us]". ${ }^{7}$ Shifting the vantage point of her travelling gaze from the 'centre' of the social, political, economic and cultural life of the nation to its 'peripheral' lands and, in particular, to the border that has accumulated a myriad of passing stories of victims and survivors, Kassabova rewrites a paradigmatic axis of thinking about the forms of representative sovereignty, emblematically associated with the capital. Though the totalitarian regime in Bulgaria did not end in such outbursts of violence as those witnessed by its neighbours, politically designed and state-imposed Nationalism expanded to threatening ends in numerous zones of invisibility such as the peripheral borderlands. The land patch between Bulgaria, Greece and Turkey was a corridor to freedom and death for those who would opt to pass through the Iron Curtain from that barbed leeway. Making it the focal point of her journey and the ensuing travelogue, Kassabova attempts to observe, from within the invisibility of buried trauma, the clandestine workings of a regime whose façade identified with a slogan reading "Socialism with a human face", obtaining much insight from local stories and from her own crossing of the now "sleepy" border in all directions. The local stories she weaves into her narrative belong to witnesses, sufferers, survivors, family members of victims, most of whom themselves migrants, more or less comfortably settled on one or the other side of the border after ethnic persecution, ungrounded police arrests, false incrimination on accusations of spying, or as a sequence of the sorrowful expulsion of ethnic minorities (like Turks or Pomaks) during the notorious Great Excursion of 1989. Collecting local stories at a time when the rigid border has started to fray, overgrown by a primordial forest or dissolved in mythic, ritual space (ember-dancing rites of purification in Strandja mountain, healing springs, the flight of doves over the Valley of Roses), perforates

\footnotetext{
${ }^{5}$ Kindle Pageless edition.

${ }^{6}$ Kindle Pageless edition.

7 The inserted phrase is a translation from the Bulgarian edition of the novel edited by Kassabova herself.
} 
the space and time of a contemporary sovereign state attempting to reconcile it to its aching anachronistic fringes, echoing Dussel's appeal to the will for life. Indicative, in this respect, is the narrator's experience of a feast of ethnic conviviality in Edirne, Turkey, with an Orthodox priest dancing at a Turkish wedding and Turks, Pomaks and Greeks attending a Christian Orthodox Easter. In spite of her frequent recourse to stereotypical representation and tendency to exoticise her encounters with Balkan 'otherness', Kassabova's narrative strives genuinely to remember the many names of cities, towns, local sites, rivers, alongside human voices and silences, in an extremely vocal text that trusts the permanence of vocality. Much like Nicholson's trust in the song of the streets of Tbilisi, she elaborates a poetics of englobing locality (or, to be more precise, regionality) where the 'periphery' operates as the modifier of dominant discourses.

In conclusion, sovereignty has become an issue in the contemporary fluctuations between personality, locality, regionality and globality. A sovereign self, the idealistic imposition of Modernity, is subject to less categorical definitions. What contemporary critics of englobing movements, like Tolstanova, Donnan, Hurd and Leutloff-Grandits detect as a tendency in contemporary art and literature, seeing their ethic and aesthetic purpose in 'listening' more than claiming firmly, is the will to expose the flimsiness of 'designed narratives', power-ridden structures of order and classification. Sovereignty, one of the imagined retreats in the vast cross-border expanse, is, nowadays, less thought of as an englobing whole. Rather, its permanence is relegated to the quest for each one of its ingredients, seeking to restore a seemingly invisible locality, individual voice and human experience, as well as the permanence of earth, water, the heavenly globe, to a forgotten narrative of life's essentials.

\section{Works Cited:}

Hurd, Madeleine, Hastings Donnan and Carolin Leutloff-Grandits. "Introduction”. Migrating Borders and Moving Times: Temporality and the Crossing of Borders, edited by Hastings Donnan, Madeleine Hurd and Carolin LeutloffGrandits. Manchester UP, 2017.

Kassabova. Kapka. Border: A Journey to the Edge of Europe. Granta, 2017.

Kostova, Ludmilla. "Victimization and Its Cures: Representations of South Eastern Europe in British Fiction and Drama of the 1990s". Betraying the Event: Constructions of Victimhood in Contemporary Cultures, edited by Fatima Fetić, Cambridge Scholars Publishing, 2009.

Nicholson, Anthea. The Banner of the Passing Clouds. Granta, 2013.

Tolstanova, Madina. "Postcolonial Theory, the Decolonial Option and Postsocialist Writing”. Postcolonial Europe? Essays on Post-Communist Literatures and Cultures. Rodopi, 2015.

---. “On Decolonizing Design”. Design Philosophy Papers, vol. 15, no. 1, 2017, 5161.

Warner, Marina. "Engendered Images”. Monuments and Maidens. Weidenfeld and Nicolson, 1985. 